\title{
Terrestrial lasergrammetry and other surveying techniques in cubature calculation
}

\begin{abstract}
In recent years, Topography measurement techniques have evolved to facilitate and automate data acquisition in the field. Indeed, the appearance of GPS reducing human resources during execution of work. Also, the evolution of laser scanning techniques has resulted in precise three dimensional readings, extremely reliable and quick to execute. These two techniques push to study the possibilities of their integrations in the various fields of application of the topography in particular in the determination of cubature. The present work proposes an experimental study on the contribution of the terrestrial lasergrammetry in the field of computation of the cubature. This study presents the importance of the use of this new technology compared to conventional methods and GPS surveys. A comparison between the methods allowed us to highlight the quality of the cubature resulting from different methods of topographic surveys.
\end{abstract}

Keywords: calculation of cubature, total station, GPS, terrestrial lasergrammetry, topography, precision, earthworks, quarries, mines, terrestrial laser scanner
Volume 5 Issue 3 - 2019

\section{Kenza Ait EL Kadi}

Department of cartography-photogrammetry, college of geomatic sciences and surveying engineering, Morocco

\begin{abstract}
Correspondence: Kenza Ait EL Kadi,Assistant professor in department of Cartography-Photogrammetry, college of geomatic sciences and surveying engineering, Agronomic and veterinary institute Hassan II, Rabat, Morocco,

Emailk.aitelkad@gmail.com
\end{abstract}

Received: November 02, 2019 | Published: November 12, 2019
Abbreviations: TLS, terrestrial laser scanner; DTM, digital terrain model; TS, total station; GPS, global positioning system; GNSS, global navigation satellite system

\section{Introduction}

Literally, cubature is the transformation of a volume of arbitrary shapes into a cube of equal volume, ${ }^{1}$ in the vocabulary of public works this term refers rather to the measurement of this volume. This measurement is generally entrusted to the surveyor whose role has been essential in all civil works, mines and quarries. It is he who raises the geometric state of the place and its evolution through the surveys of dimensioned plans which are at the base of any calculation of cubature. The determination of cubature is important in various fields such as earthworks, quarries, mines, etc. Currently the most used method to meet this need is the conventional total station survey, ${ }^{2}$ However, this technique only allows surveying, a limited number of points which prevents the faithful representation of the objects and makes the work tedious especially in the case where the geometry of the forms to be raised is complex. In addition, recent technological developments have made two innovative technologies available, namely GPS ${ }^{3}$ and Terrestrial Laser Scanners TLS. Through the advantages and richness of the raw product from SLT, ${ }^{4}$ terrestrial lasergrammetry plays an important role in calculating cubicles. ${ }^{5}$

This study is part of the comparison of cubature determination methods, including the conventional survey technique especially total station, the GPS technique and the 3D terrestrial laser scanner TLS. The general thrust of this work is to provide useful insights for all those who will have to make a choice about the most appropriate and interesting technologies to apply in their projects.

\section{Materials and methods}

\section{Study area}

It is a section of a highway under construction. The area corresponds to a portion of the excavation where the land clearing work has been completed (final state of excavation). Regarding the dimensions, it covers an area of $2437 \mathrm{~m}^{2}$ and has a perimeter of $204 \mathrm{~m}$ with a slightly rugged terrain marked by a flat shape framed by two slopes at the side. Thus, he was chosen to work with a step of $5 \mathrm{~m}$ during the GPS and total station survey (Figure 1).

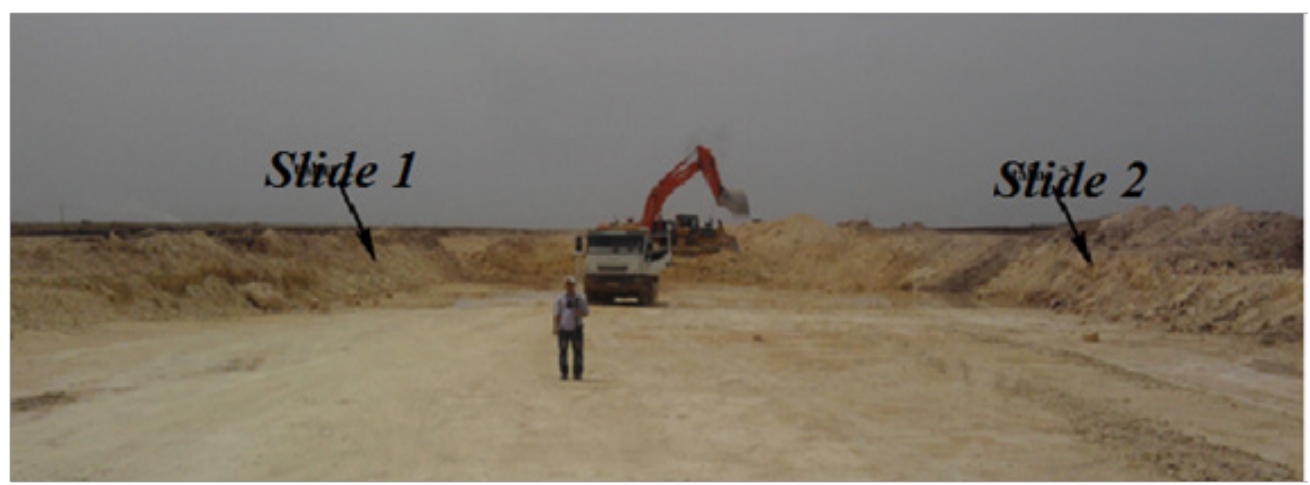

Figure I Highway section presenting the study area. 


\section{Survey of cubature by terrestrial lasergrammetry}

The scanning laser survey cannot happen, as indeed all other topographic processes, a preliminary moment of analysis and planning. In this step, taking into account the characteristics of the terrain, it is necessary to provide the method of survey, the number of stations to be implemented to be able to acquire data in sufficient quantity and quality while optimizing the time of resolution. The area of study chosen to carry out the survey is cleared so there is absence of the masks; in addition they are characterized by a not very rough relief. Thus, assuming that the 3D laser scanner only finds what it "sees" and in order to have a total coverage without creating a redundancy of data that can paralyze their management, we decided to limit ourselves to a single point of view for the survey. In relation to the resolution, we decided to use two resolutions: A resolution of $10 \mathrm{~cm}$ in horizontal, $10 \mathrm{~cm}$ in vertical and a resolution of $30 \mathrm{~cm}$ in horizontal and $10 \mathrm{~cm}$ in vertical. The purpose of using two different resolutions is to know the impact of the resolution on the cubature calculation. Another parameter that has been taken into account during planning is the layout of the point of view and the target. This is because the definition of station positions and targets has a profound impact on the progress and success of the project. The planning of the optimal location where the scanner will be placed must take into consideration certain aspects that are related to the material - such as the usual and maximum range - and the constraints related to the terrain. All of these parameters must be grouped together to ensure a good surface coverage avoiding hidden parts. Since the scanner lifts everything it "sees" it is necessary to clean the cloud of points to eliminate the noise that may distort the mesh to be created later. Another operation that is necessary is the delimitation of the scatter plot. The survey range of the laser scanner is larger than that of the survey by the GPS and the total station. In order to carry out the comparison between these different methods, it was necessary to consider the same extent, that of the survey by the classical method.

To carry out this operation, it is the contour of the survey by total station that has been used. This contour has been superimposed on the point cloud and subsequently the points outside the desired extent have been removed. A lightened display is used to not interfere with the points of the cloud as shown in (Figure 2).

Once the cloud is cleared and delineated, we proceed to mesh (Figure 3) for the establishment of our Digital Terrain Model (DTM). Once the DTM is created, we calculate the cubature. This calculation is done in two ways:

Cubature calculation with respect to a horizontal plane: In this case the cubature calculation is done between the DTM and the plane defined by the operator. In this study, we set a plan at an elevation of $857 \mathrm{~m}$. The choice of this elevation is not arbitrary but because it represents the highest point of the study area. The results of the calculations shown in Figure 4:

Calculation of volume between two DTM: In this case, the cubature calculation is done between the DTM generated from the survey carried out and the DTM corresponding to the natural terrain and which was provided by the site managers.

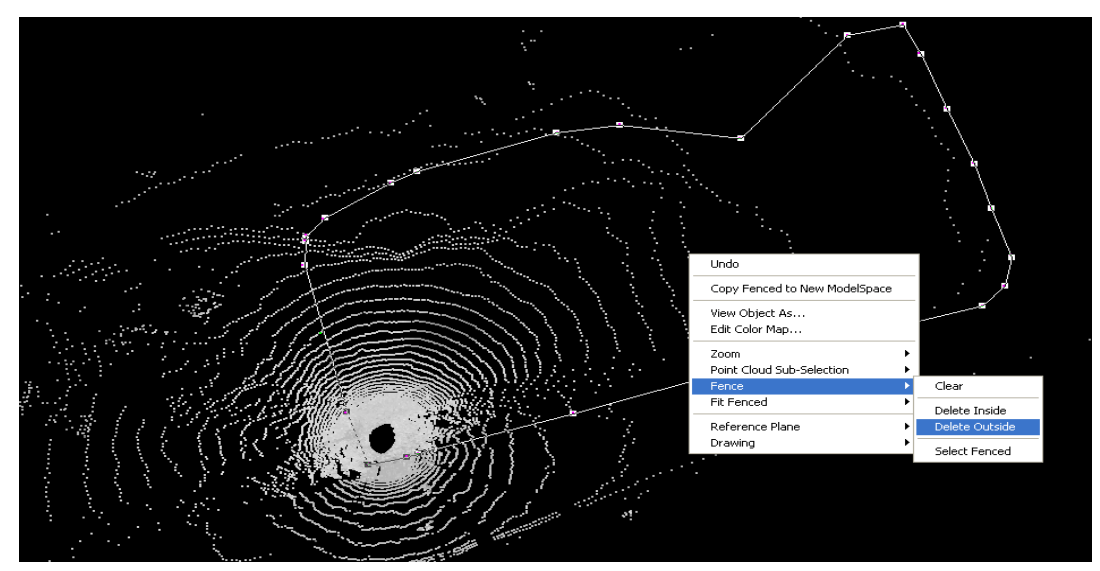

Figure 2 Superposition of the outline to the points cloud.

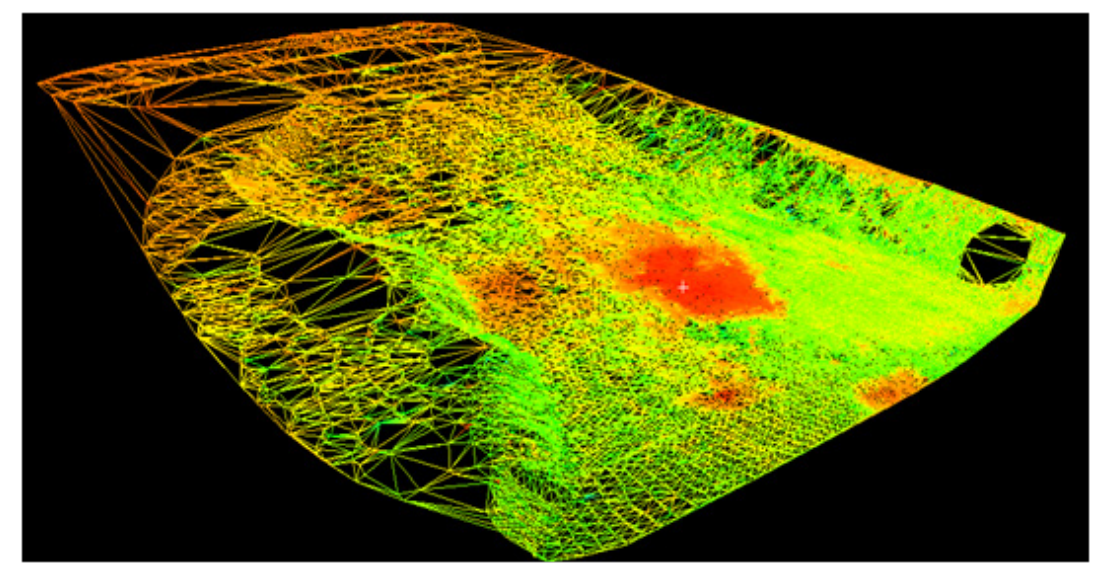

Figure 3 Mesh of the area. 


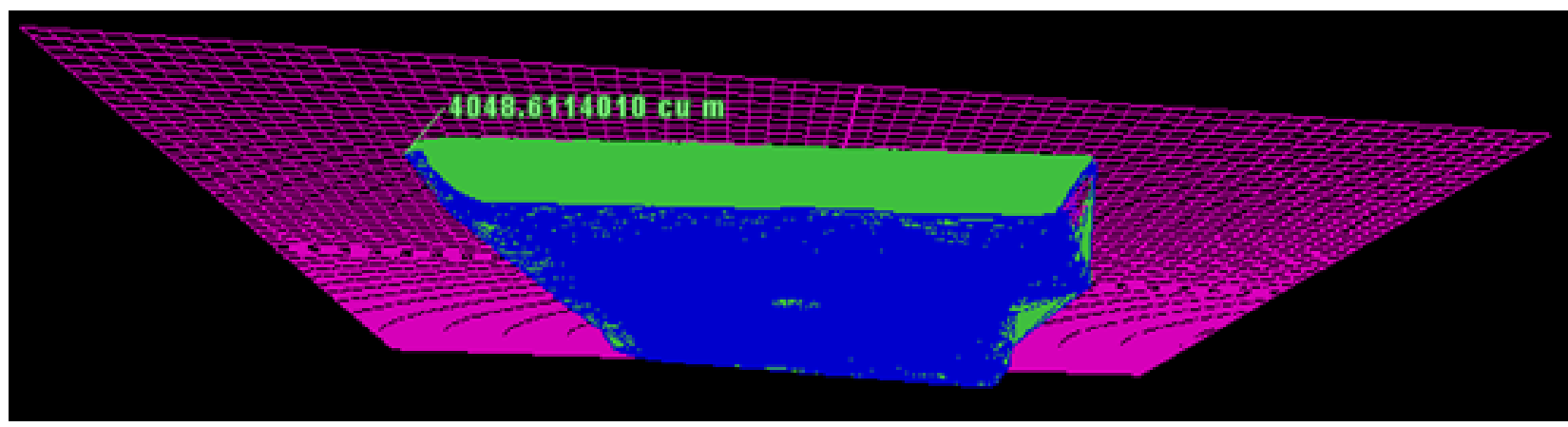

Figure 4 Calculating the volume measurements with respect to the horizontal plane $857 \mathrm{~m}(10 \mathrm{~cm} \times 10 \mathrm{~cm}$ resolution).

\section{Results and discussion}

In addition to the lasergrammetry method discussed in the previous section, two other types of surveying technique were tested on the same area. This is the total station (TS) and the GPS measurements. In the following, an analysis of the results will be carried out in order to highlight the advantages and disadvantages of each technique as well as the appropriate use cases for each. (Table 1) (Figure 5) present the results obtained from the various survey methods.

Analysis of the table and the graph allowed us to conclude that:

a) The differences between the volume from the GPS survey data and the total station data are small.

b) The results obtained from the laser scanner are different from the other two techniques $(3.24 \%$ compared to the total station survey).

This makes it possible to conclude that the non-complex terrain shape and the good conditions of the survey by GPS (no signal cut and a good geometry of the satellites) and total station (good visibility of the points and high points density) allowed a accurate representation of the ground which gave relatively identical result of cubature calculation, with regard to the 3D laser scanner survey, the results are a little different from those found by the other two methods because the survey was limited to one station which generated hidden parts (behind the talus) and therefore a lack of information. Nevertheless, the difference remains small since it does not exceed $4 \%$ of the volume, through the comparison made in the previous paragraphs, the cubature found by the three techniques using different software, different steps and different resolutions do not differ much between them. We can say then that each of the methods implemented has reached the goal sought in this study which is the calculation of cubature. However, other parameters, besides precision, must be considered in order to make a good choice as to the most appropriate technology for a given project.

Table I Cubature results of different survey techniques

\begin{tabular}{|c|c|c|c|c|c|c|}
\hline \multirow{2}{*}{$\begin{array}{l}\text { Cubatures } \\
\text { TS }\left(\mathrm{m}^{3}\right)\end{array}$} & \multirow{2}{*}{$\begin{array}{l}\text { Cubatures } \\
\text { GPS }\left(\mathrm{m}^{3}\right)\end{array}$} & \multicolumn{2}{|c|}{ TLS cubature $\left(\mathrm{m}^{3}\right)$} & \multirow{2}{*}{$\begin{array}{l}\Delta \text { Cubature } \\
(\mathrm{TS}-\mathrm{GPS})\left(\mathrm{m}^{3}\right)\end{array}$} & \multirow{2}{*}{$\begin{array}{l}\Delta \text { Cubature } \\
\left(\text { GPS-TLS) }\left(\mathrm{m}^{3}\right)\right.\end{array}$} & \multirow{2}{*}{$\begin{array}{l}\Delta \text { Cubature } \\
\left(\text { ST-TLS) }\left(\mathrm{m}^{3}\right)\right.\end{array}$} \\
\hline & & Resolution I & Resolution 2 & & & \\
\hline 4177.09 & 4171.00 & 4048.61 & 4045.16 & 6.09 & 124.11 & 130.2 \\
\hline
\end{tabular}

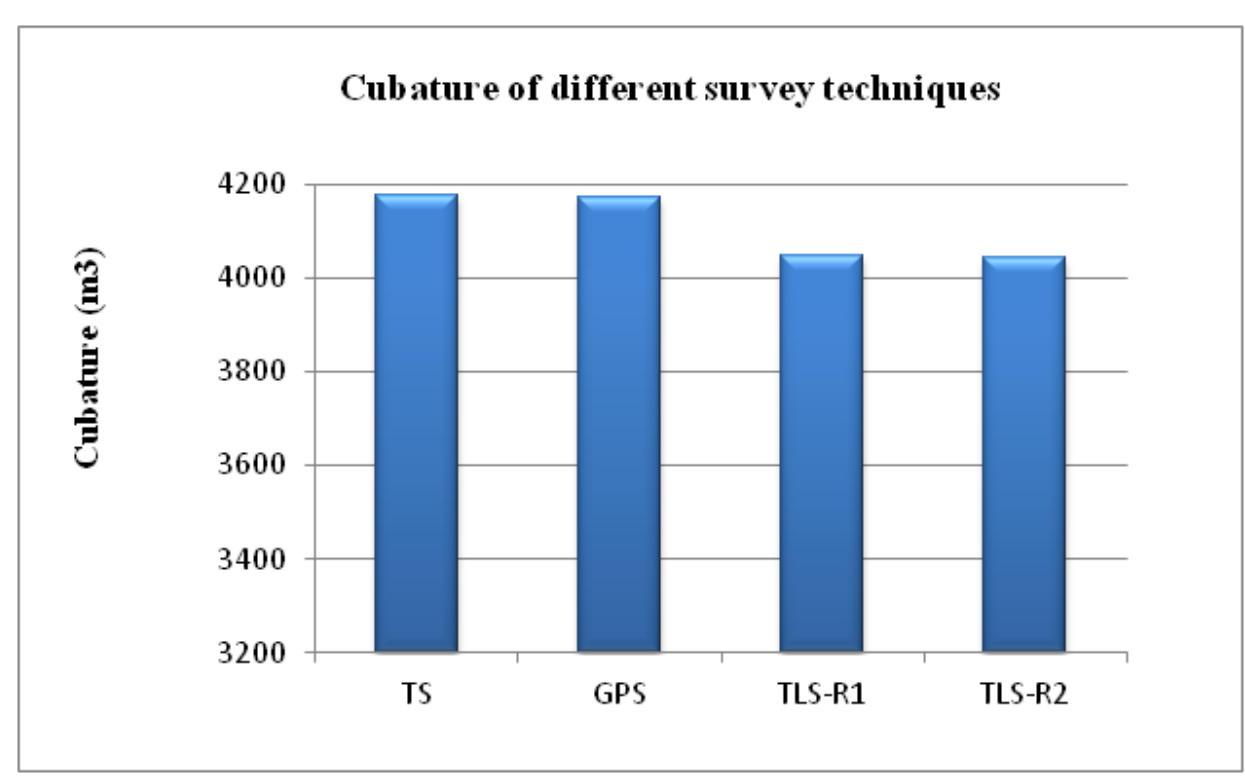

Figure $\mathbf{5}$ The results of the cubature calculation using different survey techniques. 
These parameters can relate to the time and the cost of carrying out field and office work for the choice of one of the three survey methods. A number of studies and experiments deal with this aspect of comparison between different survey methods under more complex and variable field conditions. Among these cases, an experiment was carried out in Polish by Martyna Poreba, ${ }^{6}$ to compare the GPS RTK, the total station and the 3D laser scanner in the volume calculation. The analysis of the graph above shows that there are differences between the results obtained from the different survey methods. However, these differences are small (the maximum difference does not exceed $1.5 \%$ of the volume). For this study, the specifications required that the difference between the actual volume and the volumes determined by these three survey methods should not exceed $6 \%$. The actual volume was set at a value of $6119.12 \mathrm{~m}^{3}$. In performing the calculation, the results obtained are. The three survey methods approached the actual volume and then met the required accuracy since the maximum deviation did not exceed $3 \%$ of the real volume.

\section{Conclusion}

The evolution of laser scanning techniques today results in accurate three-dimensional surveys that are extremely reliable and quick to execute. Disciplines such as topography are increasingly interested in the integration of these innovative technologies especially when it comes to complex surveys with the requirement of fast execution. This is the case for surveys that currently exploits drone imagery. On the other hand, GPS or GNSS in the global sense is increasingly needed in the cubature estimation. However, in Morocco the technique of survey by total station is still the most exploited solution and that which enjoys the confidence of engineers. This work was therefore motivated by the need to fill the lack of information concerning the use of terrestrial laser scanners in the area of cubature calculation and the comparison between these three techniques: GPS, lasergrammetry and total station. This comparison is designed to provide information in terms of quality of results and cost.

\section{Acknowledgments}

None.

\section{Conflicts of interest}

The author declares that there are no conflicts of interest.

\section{Funding}

None.

\section{References}

1. S. Milles, J Lagofun. Topographie et topométrie moderne. Calculs. 1999:2.

2. L. Guan-tu. A comparative evaluation of several methods for earthwork volume measurement. Guangdong Agricultural Sciences. 2007:8

3. JC Du, HC Teng. 3D laser scanning and GPS technology for landslide earthwork volume estimation. Automation in Construction. 2007;16(5):657-663

4. LANDES Tania, GRUSSENMEYER P, BOULAASSAL H. Les principes fondamentaux de la lasergrammétrie terrestre : acquisition, traitement des données et applications. Revue XYZ. 2011;129:25-38.

5. Szafarczyk A, Gawałkiewicz R. Defining the Cubature Changes of Historic St. Kinga Chamber in Bochnia Salt Mine, Using Laser Scanning Technology. Mathematics. 2018:35.

6. M. PORĘBA, 2009. Nowoczesne metody pomiarów mas ziemnych. Archiwum Fotogrametrii, Kartografii i Teledetekcji. 2009;19:351-361. 